\title{
Research and Application of DMAIC in Improving Fault Early Warning Process for Intelligent Production of Single Well
}

\author{
Chunlei $\mathrm{Wu}^{1}$, Yiwei Wei ${ }^{1}$, Xiaoliang $\mathrm{Chu}^{1}$, Yi Tan ${ }^{2}$ \\ ${ }^{1}$ College of Computer and Communication Engineering,China University of Petroleum (East China) \\ Qingdao, China \\ ${ }^{2}$ Beijing BeiMing DaCheng Technology Co., Ltd \\ Beijing, China \\ e-mail: wuchunlei06@163.com
}

\begin{abstract}
Improving single well failure repair efficiency by implementing Six Sigma DMAIC process for single well failure repair system in oil field. The problem is defined in strict accordance with the DMAIC process approach, clarify the scope of the process and improve the objectives. Then analyzing the main defects in single well fault repair, and evaluating and optimizing the related measurement systems. On this basis, further analysis of the root cause of the low efficiency of repair, and set the solution to the single well failure repair level of defects reduced to DPHU less than 2, while repair speed significantly improved.Finally, the key quality of the process to establish a sound control mechanism and corrective measures to ensure that improvements can be maintained. The application of DMAIC process in improving single-well failure repair can enhance the disposal ability in oilfield production process when facing unexpected problems.
\end{abstract}

Keywords: DMAIC; Six Sigma; Single well failure repair rate; quality improvement; DPHU

\section{INTRODUCTION}

With the prosperous development of intelligent information processing based on big data, oilfield enterprise, in the course of monitoring mechanical problem, also shift from artificial discrimination to intelligent approach. However, as for most oilfield enterprises like Shengli Oilfield, the repair rate of single well (53\% overall) cannot attain the expecting effect. Therefore, it is important to promote repair rate for those corporates. Because low rate will not only impede the operation of oil exploration and may even pose threats to personnel safety. It is reported that property loss caused by mismanaging the problem of paraffin-troubled well amounts to 1.5 million. In that sense, it I urgent to improve repair rate. Although we are aware of the fact that trouble validity and trouble correctness also affect, it is still uncertain about the true reasons underlying quality problems. In that case, we select Six Sigma to guide our research [1]. Generally speaking, Six Sigma is a set of techniques and tools for process define, measure, analyze, improve and control,simply called DMAIC. It seeks to remove the defects in the operation process to improve quality and serve, reduce cost and manufacturing period, in an attempt to promote competitiveness.

The main reason that DMAIC's popularity among corporates is that it provides thorough definitions on each step and a large amount of application tools to help smooth assessment and calculation[2].

This research adopts DMAIC to maximize repair rate to meet the corporations' requirements. 


\section{Quality IMPROVEMENT Of Single Well Defect}

\subsection{Definition}

Topic: After group discussion, this project aims to solve actual problems of oilfield. We plan to reduce incorrect defect discrimination rate by increasing repair rate to improve oilfield early-warning mechanism. Improvement: Project group realize that the amount of incorrectrepair cases of single well covers around $47 \%$, resulting in direct property lose amounting to 10 million. It is calculated that current repair rate DPHU is 8 . However, According to the average monthly calculation of 38 failures, the quality of the disposal process for the DPHO $=1420$, Sigma level of 4.36 is much larger than the standard.

Target: After rounds of discussion, our group aims to reduce DPHU to 2 and increase repair rate to $70 \%$ via DMAIC process.

Range: As presented in Fig .1 Organization model diagram(SIPOC), we start form unusual change of single well and end with resolving the defect.
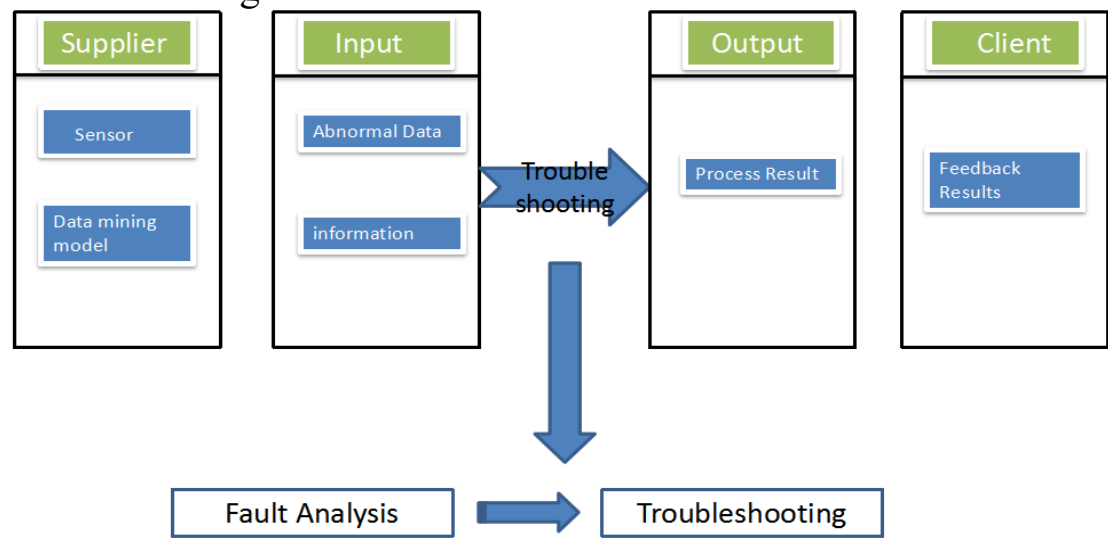

Figure 1. Organization model diagram(SIPOC)

\subsection{Measurements}

The main task for measurement process is to access measurability of the system[3]. We can effectively improve it and access certain indication within reasonableerror to avoid impact on the following operation.

The process of all repair system is focused on the repair system based on big data. And the first step is that sensors send effective information to early monitoring system after shifting the real-time data. Then the model will analyze the data and send the result to reason identification model which then, send feedbacks to operators. Core function structure is shown in Fig .2 which demonstrates that the measurability of the system is vital.

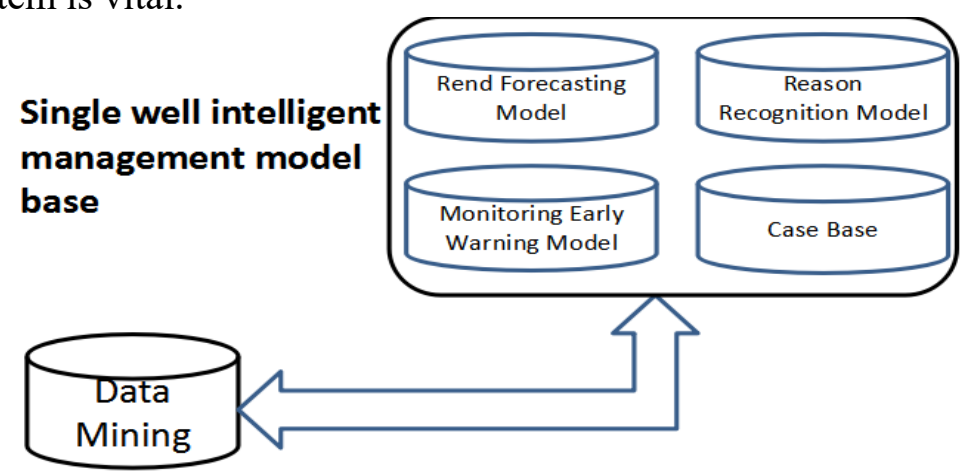

\section{Data Interface}

Figure 2. Core framework diagram 


\subsubsection{Measurement System Analysis}

As for the DMAIC process in the traditional manufacture, our experiment is supported by a set of intelligent automation. Therefore, the role of data exploration that is the first step equals to traditional manual measurement. Therefore, before further analyze, it is important to ensure the ability of the system. To test whether the data exploratory ability[4] meet the requirements or not, we select 32 paraffin precipitation single well samples as data source and put them into two different models. What we need to do is to count the consistency within two models and judge the consistence with the standard data. The result is presented in TABLE1.The greater the confidence interval, the lower the reliability of the data. Therefore, it can be judged that the model's data mining capability is obviously insufficient. After the analysis of the project team, we get the following conclusions. First of all, due to the engineering and technical personnel are too confident that the model of data mining capabilities, without any processing of the sensor data obtained by the data mining model, resulting in data noise is too large. Secondly, Due to the primitive data of pre-reserve is too small, the pattern recognition algorithm is not trained by the qualified training set, which leads to the inability to extract valid information. Data mining model analysis results (before improvement).

\section{TABLE 1. DATA MINING MODEL ANALYSIS RESULTS(BEFORE IMPROVEMENT)}

\begin{tabular}{|l|c|c|c|c|} 
& $\begin{array}{l}\text { Number of } \\
\text { test samples }\end{array}$ & $\begin{array}{l}\text { Basic Match } \\
\text { Number }\end{array}$ & $\begin{array}{l}\text { percentage } \\
(\%)\end{array}$ & $\begin{array}{l}\text { Confidence } \\
\text { interval }\end{array}$ \\
\hline $\begin{array}{l}\text { The degree of information } \\
\text { matching between models }\end{array}$ & 32 & 18 & 56.25 & $\begin{array}{l}\text { lower:41.23 } \\
\text { upper:64.75 }\end{array}$ \\
\hline $\begin{array}{l}\text { The degree to which the } \\
\text { model matches the } \\
\text { standard information }\end{array}$ & 32 & 16 & 50.00 & $\begin{array}{l}\text { lower:39.36 } \\
\text { upper:59.20 }\end{array}$ \\
\hline
\end{tabular}

According to different errors, the project team separately analyzed and put forward the solution.In response to the first question, we combined the oil field staff and the relevant data mining developers to discuss the data in advance screening, and the different sensors to advance the classification of incoming data to reduce the impact of noise.For the second question, we contacted the managers of the oilfield information center, acquired a large number of original fault information into our distributed database, and built a data training set to meet the demand.After a series of measures are implemented, the data mining capability of the system is re-evaluated. The results are shown in Table 2 . The data matching rate of the data mining model is about $84 \%$, which can basically meet the requirements of follow-up work.

\section{TABLE 2. DATA MINING MODEL ANALYSIS RESULTS(AFTER IMPROVEMENT)}

\begin{tabular}{|l|c|c|c|c|} 
& $\begin{array}{l}\text { Number of } \\
\text { test samples }\end{array}$ & $\begin{array}{l}\text { Basic Match } \\
\text { Number }\end{array}$ & $\begin{array}{l}\text { percentage } \\
(\%)\end{array}$ & $\begin{array}{l}\text { Confidence } \\
\text { interval }\end{array}$ \\
\hline $\begin{array}{l}\text { The degree of information } \\
\text { matching between models }\end{array}$ & 32 & 25 & 78.13 & $\begin{array}{l}\text { lower:58.36 } \\
\text { upper:83.54 }\end{array}$ \\
\hline $\begin{array}{l}\text { The degree to which the } \\
\text { model matches the } \\
\text { standard information }\end{array}$ & 32 & 27 & 83.38 & $\begin{array}{l}\text { lower:65.45 } \\
\text { upper:92.49 }\end{array}$ \\
\hline
\end{tabular}

\subsubsection{Model Process Capability Analysis}

After the data mining capacity reaches the required accuracy, the process capability of the monitoring and early warning model and the cause identification model at the current stage is evaluated.As shown in Fig .3 and Fig.4.Since the process is based on a virtual computer model, we cannot obtain the number of opportunities for each fault analysis error, and we cannot calculate the exact PPM value. From Fig .3 and 
Fig .4, we can conclude that there is an upward trend in inefficiency and error rate. So the process capability of the two models is obviously insufficient.

total/Invalid
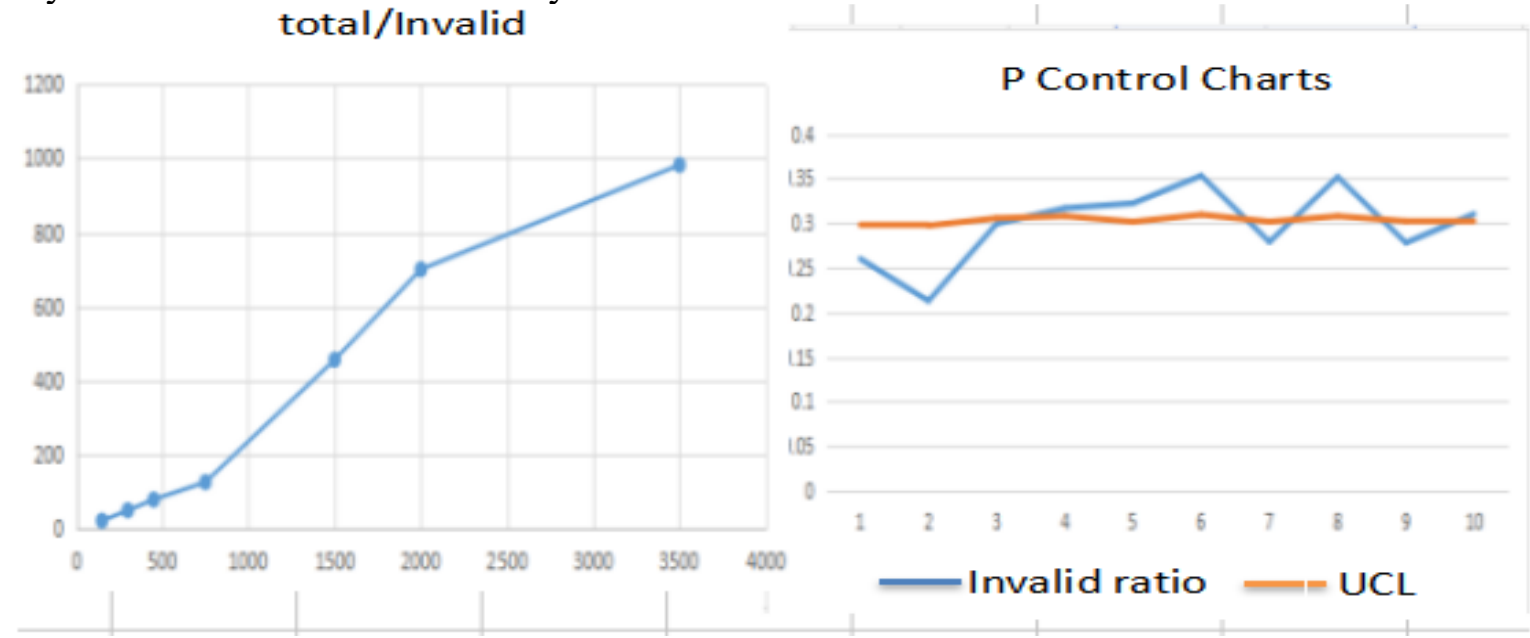

Figure 3. Monitoring and early warning model capacity assessment Diagram
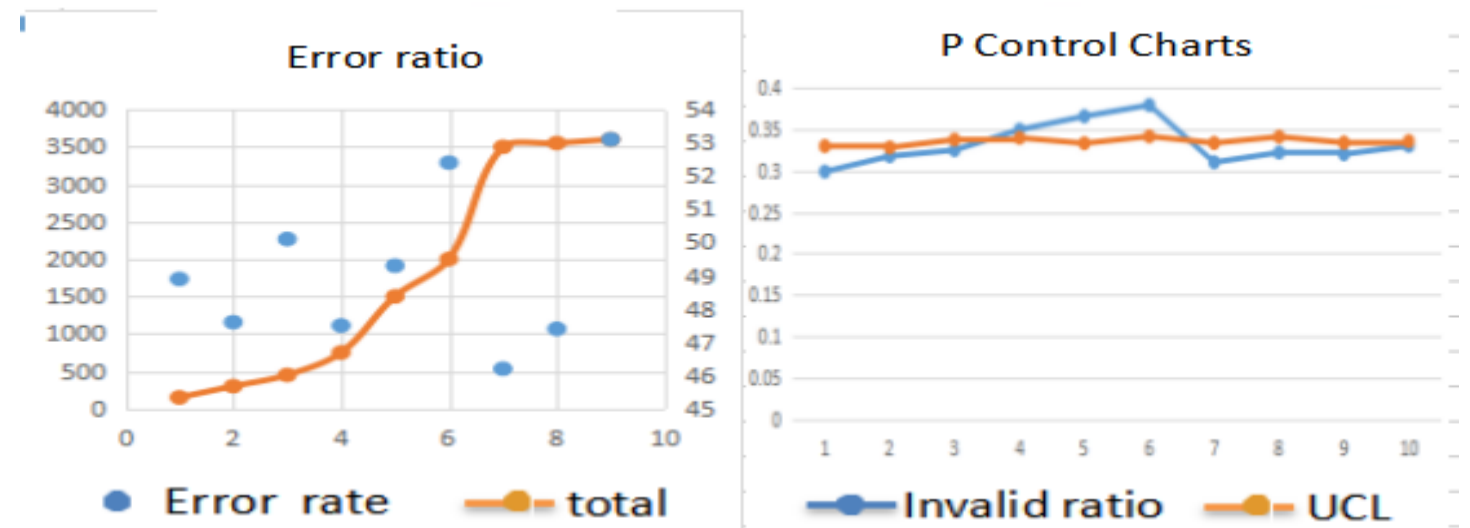

Figure 4. Cause Recognition Model Capability Assessment Diagram

\subsection{Analysis and Improvement}

Through the process capacity analysis, we can get that process repair capacity have insufficient in measurement phase. Especially the monitoring early warning model and the fault recognition model are less efficient. Therefore, the fault repair process is to be improved.

As the fault repair process model is not independent of each other, we treat all models as a holistic process for causal analysis, as shown in Fig .5.In order to detect potential impact factors. Through the brainstorming and causal analysis matrix, we can see that the main reasons for the failure of repairing failure of single well knot are parameter scale, load boundary value, power graph area threshold, cluster processing capability, algorithm time complexity. 


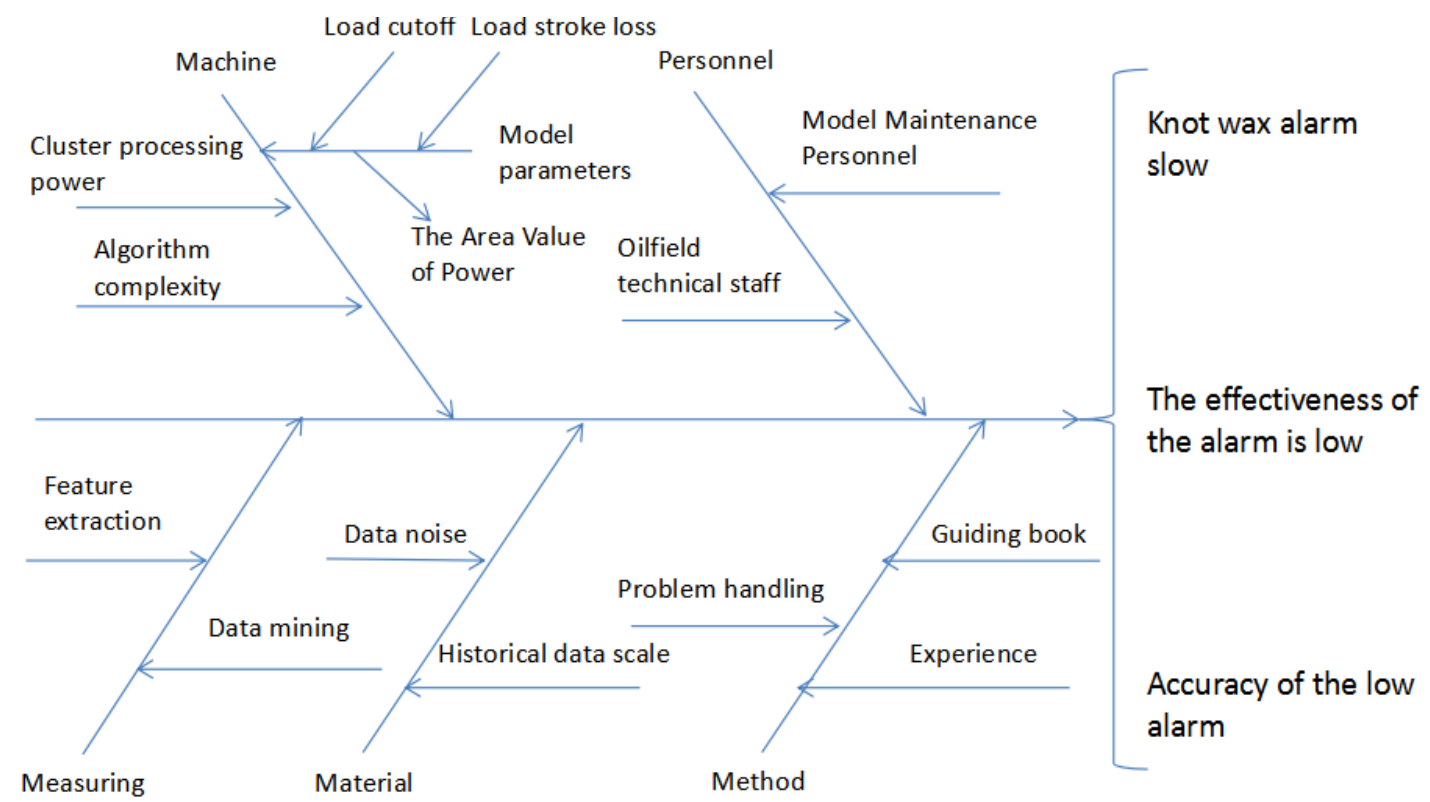

Figure 5. Fault repair cause and effect diagram

The interaction between the main factors is not significant, so the project team decided to use the onefactor method [5] to optimize the factors to improve.

\subsubsection{Load Cutoff}

First of all, we study the impact of the setting of load threshold on the efficiency of fault repair. The experimental results are shown in TABLE 3 and TABLE 4.

Through the contingency table analysis shows, The Pearson chi-square statistic is 48.25, corresponding to the $\mathrm{P}$ value is 0.0000 , it should reject the null hypothesis, which means that the load threshold has a significant effect on the success rate of fault repair. It can be seen from TABLE III and TABLE IV that the maximum load cutoff value is set at $1 \mathrm{cl}(90) \sim$ ucl $(95)$, the minimum load cutoff value (Y2) is set to be the optimum value between lcl (41) and Y2 <ucl (47).

TABLE 3. THE MAXIMUM LOAD CUTOFF SETS THEEXPERIMENTALRESULTS

\begin{tabular}{|c|c|c|c|c|}
\hline \multirow{2}{*}{$\begin{array}{l}\text { Maximum } \\
\text { Load Cutoff }\end{array}$} & \multicolumn{2}{|c|}{ Failure Case } & \multirow{2}{*}{$\begin{array}{c}\text { Successful Case } \\
\text { correct }\end{array}$} & \multirow{2}{*}{$\begin{array}{c}\text { Number of } \\
\text { samples }\end{array}$} \\
\hline & invalid & Valid/incorrect & & \\
\hline $100 \mathrm{kn}$ & 17 & 25 & 58 & 100 \\
\hline $97 \mathrm{kn}$ & 13 & 18 & 69 & 100 \\
\hline $94 \mathrm{kn}$ & 10 & 12 & 78 & 100 \\
\hline $91 \mathrm{kn}$ & 11 & 16 & 52 & 100 \\
\hline $89 \mathrm{kn}$ & 16 & 16 & 68 & 100 \\
\hline $95 \mathrm{kn}$ & 21 & 27 & 52 & 100 \\
\hline $93 \mathrm{kn}$ & 16 & 20 & 64 & 100 \\
\hline $90 \mathrm{kn}$ & 12 & 9 & 79 & \\
\hline $87 \mathrm{kn}$ & 18 & 16 & 66 & 100 \\
\hline $85 \mathrm{kn}$ & 20 & 17 & 63 & 100 \\
\hline
\end{tabular}


TABLE 4. THE MINIMUM LOAD CUTOFF SETS THE EXPERIMENTAL RESULTS

\begin{tabular}{|c|c|c|c|c|}
\hline \multirow{2}{*}{$\begin{array}{l}\text { Maximum } \\
\text { Load Cutoff }\end{array}$} & \multicolumn{2}{|c|}{ Failure Case } & \multirow{2}{*}{$\begin{array}{c}\text { Successful Case } \\
\text { correct }\end{array}$} & \multirow{2}{*}{$\begin{array}{c}\text { Number of } \\
\text { samples }\end{array}$} \\
\hline & invalid & Valid/incorrect & & \\
\hline $55 \mathrm{kn}$ & 21 & 25 & 54 & 100 \\
\hline $53 \mathrm{kn}$ & 18 & 18 & 64 & 100 \\
\hline $50 \mathrm{kn}$ & 12 & 14 & 74 & 100 \\
\hline $47 \mathrm{kn}$ & 11 & 10 & 79 & 100 \\
\hline $45 \mathrm{kn}$ & 17 & 15 & 68 & 100 \\
\hline $50 \mathrm{kn}$ & 26 & 23 & 51 & 100 \\
\hline $47 \mathrm{kn}$ & 22 & 20 & 58 & 100 \\
\hline $43 \mathrm{kn}$ & 15 & 13 & 72 & \\
\hline $41 \mathrm{kn}$ & 10 & 8 & 82 & 100 \\
\hline $38 \mathrm{kn}$ & 16 & 13 & 71 & 100 \\
\hline
\end{tabular}

\subsubsection{Area of Work Area Cutoff}

Here we explore whether the value of the area of merits and demerits wax failure success rate of repair. The experimental results are shown in TABLE 5.

From the experiment we can see the optimal cut-off value of the area is not very obvious. But we can determine the range of $\mathrm{ucl}$ is $96 \mathrm{or} \mathrm{so}, \mathrm{lcl}$ is 56 or so.Therefore, we consider the analysis of means[6] to determine the optimal value. The mean analysis is shown in Fig .6.The mean area at 78 was the best. The Area Value of Power.

TABLE 5. THE AREA VALUE OF POWER

\begin{tabular}{|c|c|c|c|c|c|c|}
\hline & Area Valu & & & ilure Case & Successful Case & Number of \\
\hline & Power & Load Cutoff & invalid & Valid/incorrect & Correct & samples \\
\hline & 105 & Optimal value & 21 & 25 & 54 & 100 \\
\hline & 102 & Optimal value & 18 & 18 & 64 & 100 \\
\hline 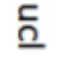 & 99 & Optimal value & 12 & 14 & 74 & 100 \\
\hline & 96 & Optimal value & 11 & 10 & 79 & 100 \\
\hline & 93 & Optimal value & 17 & 15 & 68 & 100 \\
\hline & 65 & Optimal value & 26 & 23 & 51 & 100 \\
\hline & 62 & Optimal value & 22 & 20 & 58 & 100 \\
\hline & 59 & Optimal value & 15 & 13 & 72 & 100 \\
\hline & 56 & Optimal value & 10 & 8 & 82 & 100 \\
\hline & 53 & Optimal value & 16 & 13 & 71 & 100 \\
\hline
\end{tabular}




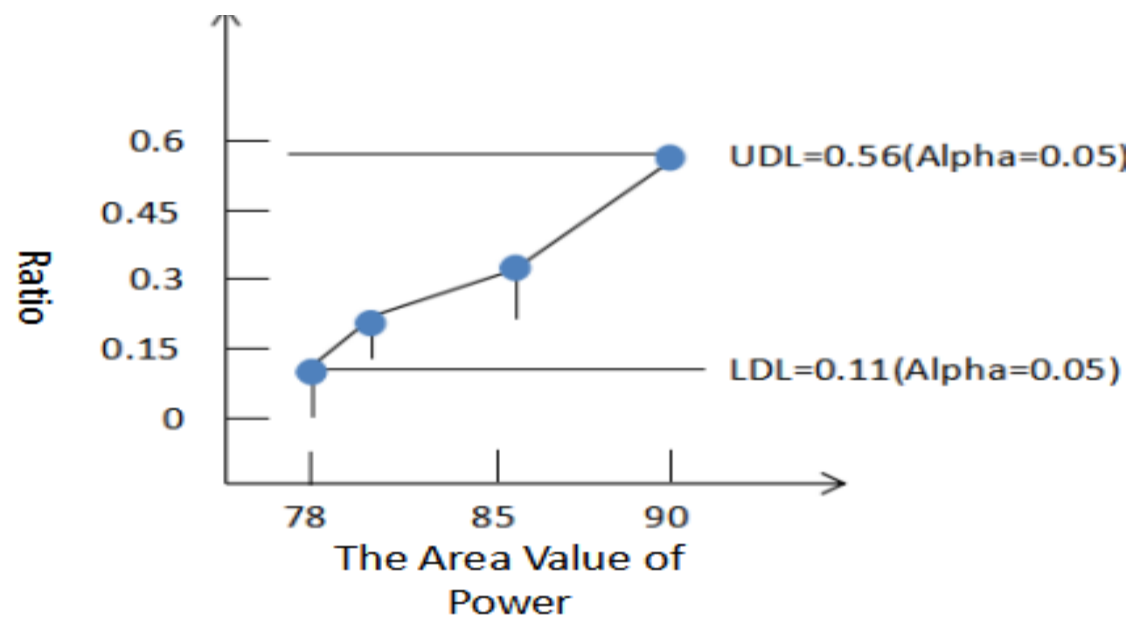

Figure 6. The Area Value Of Power(Analysis Of Means)

\subsubsection{The Critical Value of Liquid Column Weight}

Then we study the influence of the critical value of liquid column weight on the success rate. The experimental results are shown in TABLE 6.

Through the contingency table analysis shows, the Pearson chi-square statistic is 48.25, corresponding to the $\mathrm{P}$ value is 0.0000 , it should reject the null hypothesis[7], which means that the load threshold has a significant effect on the success rate of fault repair.We can see through the trend of TABLE 6.The critical value of the weight of the liquid column is set at lcl (20) ucl (30).

TABLE 6. THE CRITICAL VALUE OF LIQUID COLUMN WEIGHT

\begin{tabular}{|c|c|c|c|c|c|c|}
\hline \multicolumn{3}{|c|}{ Liquid column Load\&power } & \multicolumn{2}{|c|}{ Failure Case } & \multirow{2}{*}{$\begin{array}{c}\text { Successful Case } \\
\text { Correct }\end{array}$} & \multirow{2}{*}{$\begin{array}{c}\text { Number of } \\
\text { samples }\end{array}$} \\
\hline & & area & invalid & Valid/incorrect & & \\
\hline \multirow{5}{*}{ 드 } & 35 & Optimal value & 22 & 23 & s5 & 100 \\
\hline & 33 & Optimal value & 16 & 17 & 67 & 100 \\
\hline & 31 & Optimal value & 10 & 12 & 78 & 100 \\
\hline & 29 & Optimal value & 13 & 12 & 75 & 100 \\
\hline & 27 & Optimal value & 17 & 15 & 68 & 100 \\
\hline \multirow{5}{*}{ 뜨 } & 25 & Optimal value & 25 & 22 & 53 & 100 \\
\hline & 23 & Optimal value & 21 & 19 & 60 & 100 \\
\hline & 21 & Optimal value & 12 & 13 & 75 & \\
\hline & 19 & Optimal value & 13 & 12 & 75 & 100 \\
\hline & 17 & Optimal value & 16 & 15 & 69 & 100 \\
\hline
\end{tabular}

\subsubsection{Other Factors Analysis}

By optimizing the above three thresholds, we can improve the accuracy of the monitoring and early warning model and the cause recognition model. But there are too slow the problem in the first major factor and in the alarm[8]. After the project team analysis, we get the cluster processing capacity and algorithm time complexity is the biggest reason for speed. For the cluster processing capacity, we first increase the number of processing nodes, and secondly, we installed a number of advanced GPU, CPU to cluster processing capacity. For the complexity of the algorithm, we use a way for space-time, increase the storage device, in order to reduce processing time. After improvement, repair speed has been significantly improved, the effect shown in Fig .7. 


\begin{tabular}{|c|c}
\hline Oilfield & $\begin{array}{c}\text { Average early } \\
\text { warning time }\end{array}$ \\
\hline WW12-1 & $56 \mathrm{~min}$ \\
\hline WW13-1 & $47 \mathrm{~min}$ \\
\hline Total & $50.15 \mathrm{~min}$ \\
\hline
\end{tabular}

Figure 7. $\quad$ Statistics Of Failure Of Solid Wax In An Oilfield

\subsubsection{Control}

This researchapplies DMAIC process to improve repair rate of single well defects to meet the oilfield needs.

Effective controlling impact factors of breakdown is able to achieve preventive control[9]. In a bid to maintain the repair rate at high level after improvement, we take advantage of PCT[10] to respectively control critical factors that impact single well repair rate. And then we correct the possible factors that may result in variation.

\section{IMPROVEMENTS RESULT}

Under the condition without any special treatment, our group apply the DMAIC process in the course of repairing paraffin precipitation single wells. We find out that, via constant tracking on the process and scientific assessment, the repair rate increase from $53.33 \%$ to $73.27 \%$ and DMAIC successfully meat the expected requirements. In accordance with relative statistics we can say that this improvementbasically achieves the targeted goal and improves the oilfield control ability when confronted with oil well problems.

\section{CONCLUSION}

In this paper, we improve the single well failure efficiency in large data environment based on Six Sigma Improvement Process. In the definition stage, we analyzed and established the scope of improvement to determine the single well failure to repair the success rate of $70 \%$ or more, and to significantly improve the level of six sigma target.In the measurement phase, we abandoned the method of evaluating the artificial measurement ability, and chose to test and evaluate the data mining capability according to the different implementation environment. At the same time, we put forward the improvement method to make the data mining ability reach the system requirement level.In determining the data mining capacity of the system meet the requirements of the situation, we process the ability to repair failure assessment and found that process capacity is insufficient.In the analysis stage, we determined the most important influencing factors to the fault repairing process through the fish bone diagram, brainstorming and causal analysis.In the stage of improvement, we improved the factors of each factor by one factor analysis to achieve the best effect, and integrated evaluation, it was found that failure to repair the efficiency was significantly improved.Through a series of measures to be implement, failure to repair the basic efficiency of oil production achieve the level of intelligent production requirements. 
ACKNOWLEDGMENT This work is supported by the Research and Application Demonstration of Innovative Methods for Oil and Gas Exploitation in the Large Data Environment (No. 2015IM010300) by the Ministry of Science and Technology of China in 2015, and the 2014 ShandongProvince Young Scientist AwardFund(No.:2014BSE28032).

\section{REFERENCES}

[1] Malin Six Sigma Management (Second Edition) [M].Beijing: Renmin University of China Press, (2007).

[2] Pyedek T. The Six Sigma HandBook[M]. New York:McGraw-Hill (2003).

[3] HE Zhen, SHI Jing, SHI Liang-xing. Application of R \& R Analysis of Measurement System in Enterprise Quality Improvement [J]. Industrial Engineering, (2003),6 (3): 62-66.

[4] Pang-Ning Tan, Michael Steinbach, Vipin Kumar. Introduction to Data Mining[M]. Beijing: People's Posts and Telecommunications Press,(2009).

[5] Box G E P, Hunter W G, Hunter J S. Statistics for experiments: AnIntroduction to design,data analysis and model building[M].New York: Wiley,(1978).

[6] Ott E R. Analysis Of Means-a graphical procedure[J].Industrial Quality Control,(1976), 24(2):101109.

[7] Werner A J. Schippers. Applicability of statistical process control techniques[J].International Journal of Production Economics, (1998), 56-57:525-535.

[8] J. P. C. Tong, F. Tsung, and B. P. C. Yen.A DMAIC approach toprinted circuit board quality improvement, Int. J. Adv. Manuf. Tech.,vol. 23, pp. 523-531, (2004)

[9] F. Breyfogle. Implementing Six Sigma-Smarter Solutions Using Statistical Methods. New York: Wiley, (1999).

[10] F. A. Spring. A unifying approach to process capability indices. J.Qual. Technol. vol. 29, no. 1, pp. 49-58, (1997). 